\title{
PARA CONHECER O DIREITO POSITIVO A PARTIR DO PENSAR COMPLEXO
}

\author{
Mauro Barroso Andrés ${ }^{1}$ \\ Luiz Roberto Peel Furtado de Oliveira ${ }^{2}$ \\ Maria José de Pinho ${ }^{3}$
}

\begin{abstract}
RESUMO
Artigo que discute os paradigmas epistemológico e metodológico aplicáveis às pesquisas científicas cujo objeto seja o Direito Positivo. Apresenta as perspectivas teóricas de Hans Kelsen (Teoria Pura do Direito) e Miguel Reale (Teoria Tridimensional do Direito). Toma como referencial os valores democráticos para analisar e criticar tanto o paradigma epistemológico e metodológico tradicional, apoiado na especialização disciplinar, quanto o emergente, calcado no pensar complexo e na interdisciplinaridade e transdisciplinaridade. Conclui que os paradigmas epistemológico e metodológico emergentes promovem o diálogo e a interação tanto entre sujeitos quanto entre disciplinas, sem o abandono de suas identidades; o pensar complexo, como base epistemológica, e a interdisciplinaridade e a transdisciplinaridade, como base metodológica, são adequados à produção de conhecimento científico cujo objeto seja o Direito Positivo conforme os ideais democráticos.
\end{abstract}

Palavras-chave: Direito Positivo. Interdisciplinaridade. Pensar complexo. Transdisciplinaridade.

\section{TO KNOW THE POSITIVE LAW STARTING FROM COMPLEX THINKING}

\section{ABSTRACT}

This article discusses the epistemological and methodological paradigms applicable to scientific research whose object is Positive Law. It presents the theoretical perspectives of Hans Kelsen (Pure Theory of Law) and Miguel Reale (Three- Dimensional Theory of Law). It takes as reference the democratic values to analyze and criticize both, the traditional epistemological and methodological paradigm, supported in the disciplinary specialization, as well as the emergent one, based on the Theory of Complex Thinking and on interdisciplinarity and transdisciplinarity. It concludes that: the emergent epistemological and methodological paradigm promotes dialogue and interaction both among subjects and between disciplines, without abandoning their identities; complex thinking, as an epistemological basis, and interdisciplinarity and transdisciplinarity, as a methodological basis, are adequate to the production of scientific knowledge whose object is the Positive Law according to democratic ideals.

Keywords: Positive Law. Interdisciplinarity. Complex thinking. Transdisciplinarity.

RECEBIDO EM: 3/3/2018

ACEITO EM: 26/6/2018

\footnotetext{
${ }^{1}$ Mestre em Direito pela Universidade Gama Filho (Rio de Janeiro) e doutorando no Programa de Pós-Graduação em Letras pela Universidade Federal do Tocantins (UFT). É professor do curso de Bacharelado em Direito do Centro Universitário Tocantinense Presidente Antônio Carlos (Unitpac).maurobandres@yahoo.com.br

2 Pós-doutor em Letras (Terminologia Gramatical e Ensino de Língua Portuguesa) pela Universidade da Beira Interior (Portugal) e em Letras Clássicas (Latim), pelo Laboratório de Letras Clássicas da Universidade Federal da Paraíba. Doutor em Letras Clássicas pela Universidade de São Paulo. É professor da Universidade Federal do Tocantins (UFT). luizpeel@mail.uft.edu.br

3 Pós-doutora em Educação pela Universidade de Algarve (Portugal). Doutora em Educação pela Pontifícia Universidade Católica de São Paulo. É membro da Rede Internacional de Escolas Criativas: construindo a escola do século XXI (Riec, Coord. UB/Espanha) e professora da Universidade Federal do Tocantins (UFT).mjpgon@mail.uft.edu.br
} 
Este texto tem por escopo discutir que paradigma epistemológico e metodológico mais bem se adéqua ao estudo Direito Positivo como objeto de pesquisas científicas em um ambiente democrático, considerando os paradigmas epistemológico tradicional, fundado na perspectiva cartesiana e metodologia disciplinar, e epistemológico emergente, baseado na perspectiva do pensar complexo e metodologia inter e transdisciplinar.

O desenvolvimento deste estudo, por si mesmo, serve como combustível para a discussão que realiza, vez que se apoia no paradigma epistemológico e metodológico emergente, servindo assim, ele próprio, de material para análises de seus leitores.

O texto está organizado da seguinte forma:

a. no primeiro item trata-se da conceituação do Direito Positivo e sua condição de objeto da Ciência Jurídica, bem como da forma como tradicionalmente foram desenvolvidos seus estudos, e da correlação destes com os avanços democráticos - aborda-se as perspectivas metodológica cartesiana e teórico-metodológica kelseniana, bem como a perspectiva teórica realiana da tridimensionalidade do Direito e os corolários epistemológicos e metodológicos de sua adoção;

b. no item subsequente faz-se uma análise crítica do paradigma epistemológico e metodológico ainda dominante no Brasil (paradigma epistemológico moderno e disciplinaridade), em confronto com os ideais democráticos;

c. no terceiro item tem-se a análise dos paradigmas epistemológico e metodológico emergentes, calcados no pensar complexo e na inter e transdisciplinaridade, em relação a sua aplicação nas pesquisas que tenham por objeto o Direito Positivo em ambiente democrático.

\section{SOBRE A BUSCA DO CONHECIMENTO NO ÂMBITO DO DIREITO POSITIVO}

Preliminarmente, vale esclarecer o que se entende por Direito Positivo. Maria Helena Diniz (2014) elucida que ele abrange as normas estabelecidas e impostas pelo poder político e que regulam a vida social em determinada época e lugar, deixando clara a sua historicidade e o seu caráter cultural. Já para Reale (1998, p. 601), é "aquele que tem, já teve, ou está em vias de ter vigência e eficácia".

O Direito Positivo, como um sistema de normas postas pela organização política dominante, sempre foi uma preocupação da humanidade, mas de início era entendido como um desdobramento ou das religiões, ou da política, ou da Filosofia, ou da ética ou de uma conjugação destes; destacando-se que suas variações sociais seriam essencialmente ditadas pela cultura, pela geografia, por acontecimentos históricos específicos, etc. (MONTESQUIEU, 1996). Dessa forma, o Direito Positivo não apresentaria autonomia acentuada como objeto de pesquisa.

Com o sensível incremento da visão secular sustentada pela perspectiva positivista, no entanto, espraiada pelo mundo no início do século 19 (BOBBIO, 1995), o Direito Positivo firmou-se, ainda que tardiamente, como objeto autônomo de estudo, diferenciando-se nesta condição do conhecimento derivado dos estudos realizados sobre si. 
A visão do Direito Positivo como objeto de estudo identificado como um sistema de normas postas, independentemente de sua análise sob qualquer outra perspectiva, fortaleceu a busca por uma ciência dogmática do Direito, especialmente porque sempre esteve ligado a vários outros elementos que the seriam estranhos, mas ainda assim, muito próximos.

De resto, esta era já uma condição de praticamente todos os objetos de estudo, especialmente os inerentes à natureza humana: a complexidade. Esta condição, geral, não era diferente em relação ao Direito, e era enfrentada epistemologicamente segundo um paradigma desenhado a partir do pensamento de Descartes (1996). Este enumerou e explicou preceitos que, segundo seu entendimento, seriam simples e consistentes o bastante para fundar a produção de conhecimento por qualquer pessoa dotada de razão (mola propulsora de seu método) que assim o desejasse. Seriam eles, nesta ordem:

a. inicialmente, nunca aceitar ou utilizar algo como verdadeiro apressadamente, apenas com base numa prevenção, ou seja, deveria o investigador considerar apenas aquilo que não oferecesse qualquer dúvida ao seu espírito, de modo que não tivesse nenhuma ocasião de colocar este conhecimento em dúvida;

b. dividir cada uma das dificuldades sob exame em tantas parcelas quantas fossem possíveis e necessárias para melhor solucioná-las;

c. partir sempre dos objetos de conhecimento mais simples e mais fáceis de conhecer para os mais complexos, presumindo até mesmo uma ordem em relação àqueles que não se precedem naturalmente uns aos outros;

d. fazer continuamente relações metódicas tão completas e revisões tão gerais que restasse a certeza de nada omitir em relação ao conhecimento do objeto em estudo.

Descartes (1996) apoiava-se, portanto, na ideia de cadeias causais, que se explicariam pelo uso rigoroso, sistemático e metódico da razão, que partiria de análises minuciosa para culminar com sínteses de igual natureza.

Este pensamento, extremamente útil e que provou ser altamente eficiente em vários campos científicos, alimentou o paradigma epistemológico moderno e tradicional. Em se tratando de cientistas do Direito, Hans Kelsen (1998, p. 1) é basilar, pois elaborou o que denominou Teoria Pura do Direito, afirmando que a designação de "pura" conferida a sua Teoria do Direito "[...] significa que ela se propõe garantir um conhecimento apenas dirigido ao Direito e excluir deste conhecimento tudo quanto não pertença ao seu objeto, tudo quanto não se possa, rigorosamente, determinar como Direito [...]", pretendendo libertar a ciência jurídica de todos os elementos que lhe fossem estranhos, tomando isto como princípio metodológico fundamental, no qual as normas formariam o corpo essencial do Direito.

Se a pureza da Teoria de Kelsen, portanto, abrangia a totalidade do Direito como objeto de estudo isolado de qualquer outro, na esteira da estruturação das demais ciências, a Ciência do Direito deveria trabalhar com a máxima especialização no estudo deste objeto, o que levou à identificação dos diversos "ramos do Direito", e, consequentemente, ao desenvolvimento profícuo de estudos cada vez mais profundos, porém compartimentados e estanques entre si. Nesse processo não havia, de fato, uma preo- 
cupação direta com o retorno à totalidade do Direito Positivo, com o fato de se encontrar este perpassando todo o tecido socioestatal, cruzando vários saberes que convivem juntos, interferindo-se simultaneamente. Daí a crítica de que a Teoria Pura do Direito incorreria em um distanciamento progressivo do real exatamente por isso (FERRAZ JúNIOR, 2007), posto que, reconhecido como complexo, sob tal perspectiva, o Direito carecia de ser analisado, dividido.

Essa preocupação com o distanciamento do real em relação ao Direito, que já existia e que foi se confirmando na prática, poder-se-ia afirmar, a partir da decepção com os resultados que dele eram esperados, tais como a manutenção da paz e do equilíbrio social, a proteção contra posicionamentos autocráticos, fez com que o início do século 20 apontasse para a necessidade de uma nova perspectiva epistemológica, uma vez que "[...] o direito positivo não é [simplesmente] criação da decisão legislativa (relação de causalidade), mas surge da imputação de validade do direito a certas decisões (legislativas, judiciárias, administrativas) [...]" (FERRAZ JÚNIOR, 2007, p. 89), implicando considerar outros fatores sociais além do conteúdo normativo exposto na legislação.

Nesse sentido, importa ressaltar que os textos escritos permaneceriam, mas as sociedades e sua teia de relações mudariam constante e inexoravelmente, de modo que se deveria levar em conta a complexidade inerente ao Direito, a qual envolveria o fortalecimento dos ideais democráticos, entre os quais a isonomia (igualdade perante a legislação), a liberdade (de pensamento, crença, opinião, de posicionamento), a dinâmica social a ser regulada e a fixidez textual.

O Direito em sua complexidade e finalidade toca a todos, estudiosos ou não, em suas realidades existenciais e de convivência. É, portanto, ao real que se dirige o Direito, e é ao Direito como ele é que se pretende e que se deve conhecer. Nessa seara, Miguel Reale (2000) presta grande contribuição ao desenvolver sua Teoria Tridimensional do Direito, cujo fundamento está na demonstração de que o edifício jurídico é objeto complexo, que se corporifica a partir de três perspectivas ou dimensões, que não são excludentes umas das outras:

a. Direito como valor, a qual tem como desdobramento no plano científico-positivo a Política do Direito;

b. Direito como fato, a qual tem como desdobramento no plano científico-positivo a História do Direito, a Etnografia Jurídica e a Sociologia Jurídica;

c. Direito como norma, a qual tem como desdobramento no plano científico-positivo a Ciência do Direito ou Jurisprudência.

Goffredo Telles Júnior (2002) acompanha essa linha de raciocínio e a desdobra ao ressaltar que o termo "direito" é plurívoco e analógico, e não equívoco, uma vez que seus sentidos possíveis, apesar de variáveis, não se encontram desconexos. É plurívoco porque não designa um único objeto, uma única perspectiva da realidade, referindo-se às normas, mas também às permissões nestas insculpidas e à qualidade daquilo que se conforma ao disposto nas normas, como algo valorado como justo. Nesse sentido, focaliza essencialmente a dimensão pertinente à Ciência do Direito referida por Reale (2000): as normas (jurídicas) corporificam o Direito objetivo, que regula em abstrato as ações/condutas humanas e fatos relevantes (normalmente expressos pelas leis, regu- 
lamentos e documentação afim); as permissões configuram-se como direitos e deveres subjetivos, faculdades e comandos diversos que informam as ações/condutas humanas decorrentes das normas jurídicas, direcionados aos sujeitos de direito (pessoas naturais e jurídicas); a qualidade configura-se como a conformidade das ações/condutas com o disposto nas normas jurídicas.

O alerta de Telles Júnior (2002) nos permite inferir que, muito embora as dimensões ou perspectivas possíveis para o Direito, como objeto complexo que é, possam ser definidas ao realizarmos sua análise, a busca da produção de conhecimentos mais profundos no âmbito geral ou específico de quaisquer dessas dimensões não se realizará a contento sem que haja verdadeiro diálogo entre estas, uma vez que seria um equívoco tomar a totalidade do Direito, termo que designa um objeto plurifacetado e com múltiplos desdobramentos (TELLES JÚNIOR, 2002; REALE, 2000), como uma de suas facetas específicas.

Conhecer, conforme a lição de Agostinho Ramalho Marques Netto (2001, p. 14, grifos do autor), implica necessariamente a tarefa de "[...] construir, ou dizendo melhor, de reconstruir, de aprimorar os conhecimentos anteriores. Se conhecimento é, de fato, um processo de retificação de verdades estabelecidas [...]", é preciso atentar para o fato de que, ainda segundo este autor, "[...] o sujeito não vai em branco observar o objeto. [Já que] Quem não sabe não pesquisa [...]"; desse modo, "[...] se é sobre o objeto de conhecimento que recaem todas as pesquisas, é claro que o sujeito constrói seu próprio objeto. A preocupação do pesquisador, antes de ser real, é teórica [...]". Daí a importância de serem traçadas as pautas de nosso objeto de estudo, como se tem feito até aqui, sem perder de vista a complexidade em que se insere. Sem dúvida alguma a referência ao Direito sob sua perspectiva positiva, no sentido de objeto concretamente observável, traz ainda a referência ao fenômeno normativo, cuja existência somente pode ser atestada no seio da convivência humana, ou seja, em sociedade. Daí o conhecido brocardo romano cuja origem é atribuída a Ulpiano: Ubi homo, ibi societas; ubi societas, ibi ius "onde está o homem, está a sociedade; onde está a sociedade, está o direito".

Nas organizações políticas dominantes e institucionalizadas da atualidade - os Estados de Direito contemporâneos - o Direito Positivo manifesta-se como texto, essencialmente prescritivo em sua totalidade (vide Constituições dos Estados), sendo dotado de função pragmática que o configura como um conjunto de mensagens que tem por finalidade dirigir, orientar ou regular as ações e condutas humanas às quais se refere; daí a juridicidade das ações e condutas praticadas concretamente pelas pessoas em sua convivência, bem como seus desdobramentos deônticos (ordens, permissões, proibições, autorizações, etc.), dependerem da preexistência do Direito Positivo (ROBLES, 1996).

Normativo, basicamente textual e emanado do poder político institucionalizado, o Direito Positivo configura-se como um sistema (pressupondo ordem e organização) essencialmente constituído de comandos, permissões e declarações que apenas podem ser (re)conhecidos pelos membros da sociedade, em geral, a partir do momento mesmo em que são expressos segundo linguagem adequada a sua compreensão tão profunda e uniforme quanto possível, em se considerando que sua função primordial é contribuir eficazmente para a manutenção da ordem, da paz e do equilíbrio sociais. 
A linguagem humana, marcada por sua riqueza e complexidade, é instrumento de mediação entre as pessoas (naturais e jurídicas) que permite os relacionamentos, base da convivência também da conservação, do desenvolvimento e do compartilhamento de saberes.

Isso posto, se o Direito é, essencialmente, linguagem, seu funcionamento parte de pressupostos linguísticos, de modo que ele tem sua sustentação na plenitude da palavra: "[...] produz sentido, dialoga na sua aplicação, desde que a hermenêutica nos mostrou que 'somos um diálogo'" (STEIN, 2014, p. 9).

Como a sociedade brasileira se pretende democrática, cabe um alerta: os Estados de Direito e o Direito Positivo configuram-se como pilares de sustentação do processo democrático, abrangendo o último, em regra, todas as atividades sociais e políticas, inclusive da própria autorregulação, e é desenvolvido a partir dos fenômenos e relações sociais que não só são focalizados no âmbito da Ciência Jurídica, mas também do processo político como um todo; o Direito Positivo, nesse sentido, é influenciado e influi nas mais importantes teias de relacionamento social, não lhe escapando a pertinente ao desenvolvimento tecnológico e científico.

Perseguimos a democracia, e, em um primeiro momento, a existência de Estados de Direito pareceria aos mais desavisados ser o bastante para sua consecução, contudo não o é, posto que diante da evolução humana, a democracia não é uma construção que chegue ao fim, e sim, um eterno construir. Daí a complexidade que caracteriza o mundo jurídico se desnudar ainda mais: como concretizar os princípios clássicos e fundamentais da democracia, entre os quais ressaltamos o da isonomia, que pressupõe o Direito Positivo, e o da liberdade, que pressupõe a possibilidade de pluralidade e o conhecimento em toda sua pujança (escolhas e decisões realmente livres), sem ter por referencial a complexidade?

Se o que se deseja é conhecer o Direito Positivo, não se pode fazê-lo deixando de lado seu papel na busca contínua pela realização democrática, o que envolve o seu processo de gestação e elaboração, passando por sua interpretação e prosseguindo até sua aplicação em meio a essa dinâmica. Estado Democrático de Direito ou Estado de Direito Democrático são expressões que ilustram bem o quanto os fundamentos democráticos orientam o sistema jurídico em todos os momentos, até mesmo no balizamento dos textos jurídicos e de seus processos de elaboração e de interpretação/aplicação.

Tomemos ilustrativamente algumas disposições contidas na Constituição da República Federativa do Brasil de 1988 (CRFB/1988) - Artigo 1ㅇ, caput, Inciso V e Parágrafo Único (BRASIL, 2018a) - e na Lei de Introdução às Normas do Direito Brasileiro (LINDB), nominação conferida atualmente ao Decreto-Lei n. 4.657, de 4 de setembro de 1942 (em vigor com as atualizações pertinentes) - Artigo 5으, caput e Inciso II (BRASIL, 2018b) - para desenvolvimento de sucinta análise comprobatória de nossas asserções:

CRFB/1988 (grifos nossos)

Art. 1ㅇ A República Federativa do Brasil, formada pela união indissolúvel dos Estados e Municípios e do Distrito Federal, constitui-se em Estado Democrático de Direito e tem como fundamentos:

$[\ldots]$ 
V - o pluralismo político.

Parágrafo único. Todo o poder emana do povo, que o exerce por meio de representantes eleitos ou diretamente, nos termos desta Constituição.

Art. 5 o Todos são iguais perante a lei, sem distinção de qualquer natureza, garantindo-se aos brasileiros e aos estrangeiros residentes no País a inviolabilidade do direito à vida, à liberdade, à igualdade, à segurança e à propriedade, nos termos seguintes:

$[\ldots]$

II - ninguém será obrigado a fazer ou deixar de fazer alguma coisa senão em virtude de lei;

[...]

LINDB (grifos nossos)

Art. 3 Ninguém se escusa de cumprir a lei, alegando que não a conhece.

Art. 4 Quando a lei for omissa, o juiz decidirá o caso de acordo com a analogia, os costumes e os princípios gerais de direito.

Art. $5 \mathrm{Na}$ aplicação da lei, o juiz atenderá aos fins sociais a que ela se dirige e às exigências do bem comum.

Os dispositivos anteriormente destacados permitem inferir que a aplicação prática do Direito Positivo deve levar em consideração os fatos da vida social ( $v$. g. costumes e pluralismo), o valor de tais fatos para a sociedade ( $v$. $g$. fins sociais, exigências do bem comum, democracia) e as normas (textos normativos) que em relação a tais fatos dispõem de alguma forma.

O exposto até aqui permite afirmar que a Teoria Tridimensional do Direito realiana (REALE, 2000) mostra-se extremamente útil como base teórica para estudos e pesquisas que tenham por objeto o Direito em qualquer de suas dimensões.

$E$, reconhecendo a linguagem como mediadora no processo de tomadas de decisão e condutas no âmbito individual interno (consciência reflexiva) e externo (agir comunicativo no meio social) do sujeito, mostra-se de extrema valia a Teoria do Agir Comunicativo, formulada por Jürgen Habermas (2002, p. 105-106), a qual, em síntese apertada, focaliza as potencialidades da linguagem para "recriar" novas formas de relacionamento social mediante as múltiplas intervenções que, por meio da linguagem, tornam-se possíveis no mundo da vida; em especial nos espaços públicos democráticos, em que "a autoridade pública de um consenso alcançado discursivamente, sob condição de poder dizer não ao final, não pode ser substituída pelos juízos privados dos indivíduos que sabem mais".

Importa-nos, portanto, estarmos atentos à dinâmica social em todos os seus desdobramentos, incluindo os que ocorreram no campo das Ciências, uma vez que, o que se aceita como racional num dado tempo e lugar, pode não sê-lo sob outras condições epistêmicas, em outro contexto, caso varie ou o público, ou o tempo, ou o lugar/circunstâncias, etc. (HABERMAS, 2002).

O processo de produção de sentido dos discursos jurídicos, portanto, sua circulação e consumo devem ser abertos à sociedade, uma vez que este ciclo é influenciado pelas condições mesmas em que se deu a produção dos textos, especialmente porque as palavras da lei ou de textos técnico-científicos a elas relacionados não são unívocas, 
podendo variar em razão de inúmeros fatores. É por tal razão que Eduardo Carlos Bianca Bittar (2009, p. 89-90) leciona que "a interpretatividade é uma qualidade que perpassa a todos os discursos jurídicos (normativo, burocrático, decisório, científico)", de modo que a hermenêutica é vista como importante ferramenta para os juristas, tratando-se da ciência da interpretação.

A aplicação escorreita do Direito Positivo, na busca de sua realização democrática, implica ultrapassar a reprodução pura e simples dos termos contidos nos textos jurídicos e adentrar a outros campos disciplinares, como deixam entrever análises como a de Lenio Luiz Streck (2014, p. 19), que adverte quanto ao imperativo de se elaborar crítica à hermenêutica jurídica tradicional por meio da fenomenologia hermenêutica, em que o horizonte do sentido é dado pela compreensão, e o que pode ser compreendido é a linguagem, que "não é simplesmente objeto, e sim, horizonte aberto e estruturado e a interpretação faz surgir o sentido"; e a de Ricardo Maurício Freire Soares (2010, p. 19), para quem indagar sobre a hermenêutica, a interpretação e a correlata decisão no campo jurídico implica passar, "inelutavelmente, pelo estudo das relações comunicativas em sociedade e pela investigação do papel desempenhado pela linguagem, nos quadros da existência humana".

No tocante à obtenção de conhecimentos científicos mais profundos e consistentes, ${ }^{4}$ e que tenham por objeto o Direito em quaisquer de suas dimensões, inclusive as pertinentes à interpretação e aplicação escorreita do Direito Positivo para sua aplicação, o estudo realizado até aqui sugere que a adoção de perspectivas unidimensionais ou unidisciplinares, essencialmente monologais, estreitas e estanques, por estudiosos e/ou profissionais da área jurídica, mostra-se inadequada ao enfrentamento deste desafio. Abre-se assim espaço para postura alinhada com o pensamento de Gaston Bachelard (1978, p. 164):

Na realidade, não há fenômenos simples; o fenômeno é uma trama de relações. Não há natureza simples, substância simples; a substância é uma contextura de atributos. Não há idéia simples, porque uma idéia simples, como viu muito bem Dupréel, deve ser inserida, para ser compreendida, num sistema complexo de pensamentos e de experiências. A aplicação é complicação. As idéias simples são hipóteses de trabalho, conceitos de trabalho, que deverão ser revistos para receberem seu devido valor epistemológico. As idéias simples não são a base definitiva do conhecimento; aparecerão por conseguinte num outro aspecto quando as colocarem numa perspectiva de simplificação a partir das idéias completas.

Em meio a tal contexto, não se pode deixar de lado o reconhecimento de que a complexidade, que cerca o Direito em todas as suas dimensões foi característica da realidade apontada por Bachelard (1978) e bem compreendida e descrita por Edgar Morin e Jean-Louis Le Moigne (2000), devendo ser enfrentada de outro modo, sob outra perspectiva epistemológica, ressaltando estes autores que o maior desafio do pensar contemporâneo está em assumir efetivamente esta postura.

\footnotetext{
${ }^{4}$ No sentido de ser construído a partir do diálogo entre teorias de áreas diversas e relacionadas por meio da tessitura de uma teia de conceitos e relações bem concatenada, coesa e congruente, resultante de seu entrelaçamento. 
Isso se evidencia ainda mais no campo do Direito Positivo, que se insere em zona natural e inegavelmente complexa da realidade humana e do saber, uma vez que estudos compartimentados em sua dimensão normativa (legislação e precedentes) jamais serão suficientes, por si mesmos, para dar conta das problemáticas que envolvem o conhecimento do Direito e sua aplicação, uma vez que é preciso perquirir sobre sua legitimidade (valoração política das normas pelo corpo social) perante o contexto social e as situações concretas que pretende regular (fatos), tudo a partir da interpretação de seu discurso e textos (Hermenêutica Jurídica).

\section{SOBRE O PARADIGMA EPISTEMOLÓGICO AINDA DOMINANTE NO BRASIL}

A produção de conhecimento ainda se encontra fortemente alicerçada na perspectiva unidisciplinar, como bem faz perceber Oppenheimer (1958 apud POMBO, 2017a [sic]), valendo a transcrição de suas considerações, dada sua acuidade:

Hoje, não são só os nossos reis que não sabem matemática mas também os nossos filósofos não sabem matemática e, para ir um pouco mais longe, são também os nossos matemáticos que não sabem matemática. Cada um deles conhece apenas um ramo do assunto e escutam-se uns aos outros com um respeito fraternal e honesto. (...) O conhecimento científico hoje não se traduz num enriquecimento da cultura geral. Pelo contrário, é posse de comunidades altamente especializadas que se interessam muito por ele, que gostariam de o partilhar, que se esforçam por o comunicar mas não faz parte do entendimento humano comum... O que temos em comum são os simples meios pelos quais aprendemos a viver, a falar e a trabaIhar juntos. Para além disso, temos as disciplinas especializadas que se desenvolveram como os dedos da mão: unidos na origem mas já sem contacto. ${ }^{5}$

Tal situação é reforçada no âmbito brasileiro, uma vez que é preciso lembrar que o "mundo acadêmico" é também essencialmente balizado pela perspectiva jurídico-positiva, especialmente na esfera das instituições de natureza pública. Dessa forma, orienta-se pelos termos estabelecidos na Constituição que vige e que a todos obriga: Estado, sociedade e indivíduos.

Em nossa CRFB/1988 tem-se disposto que a educação é um direito social (artigo 60), e que é "direito de todos e dever do Estado e da família, [e que] será promovida e incentivada com a colaboração da sociedade, visando ao pleno desenvolvimento da pessoa, seu preparo para o exercício da cidadania e sua qualificação para o trabalho" (artigo 205), sendo dirigida no Brasil pelo poder público (artigo 24, IX), sem embargo da autonomia prevista para as universidades (artigo 207). ${ }^{6}$

As Instituições de Educação Superior (IES), especialmente as públicas, configuram-se, portanto, como centros hegemônicos produtores (pesquisa), irradiadores (ensino) e de aplicação (extensão) de conhecimento, cujas atividades são fundamentalmente orien-

Referência da obra consultada apresentada por Pombo: OPPENHEIMER, J. Robert. The tree of knowledge, Harper's, 217, p. 55-57, 1958.

${ }^{6}$ Neste campo, há espaço para discussões muitíssimo mais profundas e que não cabem nos limites deste trabalho. Cremos, contudo, que as vivências de todos os leitores serão suficientes para conduzi-los com acerto. Diretrizes Curriculares Nacionais e instrumento de avaliação para quaisquer cursos superiores ilustram bem o traçado paradigmático adotado, que desconsidera claramente particularidades regionais concretas, por exemplo. 
tadas pela regulamentação estatal. Nesta, sobressai a atuação claramente voltada para o atendimento do mercado de trabalho, conforme estabelecido constitucionalmente, com todos os desdobramentos que daí se originam: suas pautas de atuação são fortemente traçadas em consonância com os apelos do capitalismo e das pressões políticas; educandos devem ser formados para amealhar certa parcela de conhecimento e exercitá-la com maestria, não se relevando a preocupação com o desenvolvimento intelectual necessário para a produção criativa ou crítica de conhecimento.

Sendo assim, a produção de conhecimento é direcionada e seu paradigma hegemônico apoia-se na ideia de disciplinaridade, buscando-se formar, por exemplo, bons médicos e ótimos pediatras; bons engenheiros e ótimos engenheiros de estradas, etc.

Nas palavras de Minayo (2016), a disciplinaridade traduz-se num "pensamento único que em pesquisas e ensino aporta uma ótica unidisciplinar e fechada" - situação ainda hoje predominante, baseada na adoção de paradigma científico de base cartesiana (decompor questões complexas em outras mais simples para compreendê-la), à qual Moraes (2004, p. 43) faz importante crítica, em virtude de provocar a "fragmentação de nosso pensamento, a unilateralidade de nossa visão".

Contra esse contexto, Santos (2016) também se manifesta, realçando que ele se encontra na base da crise de identidade enfrentada pelas IES no tocante à perspectiva que deve orientar sua atuação.

Se o desejado é o desenvolvimento de uma sociedade democrática em essência, e não somente em aparência, a coletividade encontra-se diante de uma encruzilhada: a produção de conhecimento deve ser aberta a perspectivas novas, amplas, críticas e criativas, ou deve dar-se sob encomenda do mercado, de modo a ser eficaz para este e satisfatória para interesses econômicos, direcionada portanto, e excludente de outras perspectivas e interesses "menores" (leia-se "menos ou não lucrativos")?

Segue, na mesma linha de pensamento, Santos (2002), ao considerar a globalização como um processo que se realiza a partir de centros econômicos e científicos hegemônicos, e ao qual se refere como globalização neoliberal hegemônica, que se encontra a par com o capitalismo global, e que exigiria uma resposta à altura: uma globalização contra-hegemônica, a fim de que a diversidade de alternativas existentes, lastreadas nas experiências e racionalidades que se situam para além dos centros e paradigmas dominantes, possam ter voz e vez, sendo consideradas como possibilidades válidas e concretas (viés efetivamente democrático).

Diante de um fenômeno com o alcance e o peso da globalização, mundial e irresistível, se adotada a ótica dominante, torna-se natural que os processos econômicos e de desenvolvimento tecnológico e científico acabem por traduzir os conceitos, interesses e valores dos centros hegemônicos. As disposições constitucionais brasileiras em vigor deixam isso bastante evidente. Dessa forma, esses centros obtêm certa estabilidade e previsibilidade por tais arranjos paradigmáticos, e, mesmo que muitos discursos públicos soem altruístas, a realidade é que, por exemplo, não se investe consistentemente em pesquisa farmacêutica que não vise a produzir resultados "comerciais", por mais relevante que a questão se mostre pelas perspectivas científica e humanística. 
Não se desconhece que o paradigma ainda predominante muito contribuiu e pode contribuir para o desenvolvimento da humanidade, até porque se harmoniza com o modelo econômico capitalista em seus moldes tradicionais, o que naturalmente sempre acabará por trazer alguns benefícios.

Ocorre que esse pilar de sustentação da globalização hegemônica está fatigado e em processo de alteração, iniciando-se um ciclo mundial de revisão de prioridades, com especial fortalecimento da importância de demandas sociais antes negligenciadas, como as ligadas à qualidade de vida em geral e à manutenção da convivência pacífica e harmônica, valorizando-se a pluralidade e a diversidade. Dessa forma, há um movimento que leva ao rompimento com a prática da "ocultação" das alternatividades (de práticas, de modelos, de conhecimentos, etc.), referida por Santos (2002), quando suas ausências sequer eram percebidas, muitas vezes com grande prejuízo para as sociedades e Estados.

Nesse sentido, vale relembrar a fala de George Soros (1998, p. 13) em depoimento ao Congresso dos Estados Unidos da América:

O sistema capitalista global, que foi responsável pela extraordinária prosperidade deste país na década de 1980, está se rompendo. O atual declínio do mercado acionário dos Estados Unidos é apenas um sintoma, e um sintoma tardio, dos problemas mais profundos que estão afligindo a economia mundial [...].

Ressalte-se ainda que o século 20 foi também palco de amplos e profundos avanços político-democráticos, tecnológicos e científicos, cujos desdobramentos levaram ao respeito e à valorização da diversidade, à alteração da percepção de espaço/tempo e à intensificação da imprevisibilidade, ao surgimento da "desordem" e das incertezas advindas, como observa Morin (1999), de modo que

todos os problemas se situam em um nível global e, por isso, devemos mobilizar a nossa atitude não só para os contextualizar, mas ainda para os mundializar, para os globalizar; devemos, em seguida, partir do global para o particular e do particular para o global, que é o sentido da frase de Pascal: "Não posso conhecer o todo se não conhecer particularmente as partes, e não posso conhecer as partes se não conhecer o todo" (MORIN, 2003, p. 14).

Diante de tal contexto, dúvidas consistentes não podem restar quanto à pertinência de se redesenhar o paradigma epistemológico que deverá dominar doravante, reconfigurando-se o adotado tradicionalmente e ainda dominante, cujas linhas foram traçadas em momento histórico com características muito diferenciadas das que ora existem e que caracterizam o presente; tal como o fortalecimento dos ideais democráticos calcados no reconhecimento cada vez mais robusto de que o respeito ao diálogo, à alternatividade, à pluralidade e à diversidade fortalece e realiza mais plenamente a dignidade humana em suas necessidades.

Nesse diapasão, o conhecimento não deve ser considerado um fim em si mesmo, tampouco deve servir apenas a certas categorias sociais que dele possam usufruir por seus recursos econômicos ou políticos; deve, isto sim, ser um meio para promover a dignidade humana. Caso fosse diferente, os balizamentos éticos, reconhecidos como essenciais atualmente, não teriam o menor sentido. Não haveria limites e imperariam 
os desígnios e direcionamentos impostos pela ideologia capitalista mais crua, e os que detivessem o poder econômico imporiam seus interesses de forma plena, aniquilando fortemente a diversidade, a pluralidade, as diferenças (não as desigualdades sociais). Note-se que, no mundo capitalista e voltado para o econômico, monopólios e cartéis são apreciados pelos que os conseguem estabelecer.

Segundo Andrés (2017), as atividades humanas conduzidas no âmbito das Ciências não podem ser ditatorial e preconceituosamente (o que é paradoxal em Ciência!) tratadas, como decorre em desdobramento ao pensamento de Kuhn (2006), em que apenas a perspectiva da comunidade científica, ou de determinada parte dela, é considerada válida. A influência dos ideais democráticos e da ética devem se fazer presentes, inclusive e tanto quanto possível, levando a modificações na legislação regulatória da educação.

Sob tal ponto de vista, devem ser levadas em conta as influências externas havidas sobre os atores que buscam produzir conhecimento científico, uma vez que se configuram como variáveis que influenciam no resultado de tal produção. Logo, sua desconsideração sob a perspectiva metodológica levaria, curiosamente, a comunidade científica a deixar de aplicar a si tudo o que exige que seja aplicado para que o conhecimento produzido seja reconhecido como válido. As IES e os seus parâmetros de atuação são criações humanas e relacionais, e como tal devem ser considerados.

\section{PENSAR COMPLEXO APLICADO AO DIREITO POSITIVO NAS DEMOCRACIAS}

O sobrevoo contextual realizado evidencia a inolvidável complexidade que cerca os objetos de estudo em geral, e, sobretudo, os ligados às humanidades, como é o caso do Direito, bem como a necessidade de se encontrar uma nova forma para seu enfrentamento, com o intuito de produzir conhecimento, o que se deu a perceber exata e justamente pela expansão do conhecimento por via disciplinar segundo o paradigma epistemológico tradicional, que o fez chegar aos limites traçados pela compartimentação imposta por este modelo (disciplinaridade), fazendo-se necessário ultrapassá-los.

O Direito é aceito hoje essencialmente como "um só", como um sistema de normas estabelecido e ordenado pelo poder político institucionalizado (quando assume também caráter jurídico com a promulgação ou outorga de uma Constituição e os poderes constituídos), a partir de fatos, interesses e valores que são regulados e protegidos ou "atacados" tendo em vista uma determinada finalidade, no caso dos Estados democráticos, o bem comum.

Sob tal perspectiva, o pensar complexo, a aceitação da realidade como complexa, e da incerteza como seu signo, parece ser o ponto de partida para inúmeros estudos pertinentes ao Direito Positivo. Morin e Le Moigne (2000), valendo-se da etimologia do termo complexus, explica que a realidade é sempre fruto de algo que é "tecido conjuntamente", cabendo ao paradigma da complexidade juntar tudo e distinguir, em vez de disjuntar e reduzir, como se dá pela perspectiva tradicional, informada pelo Princípio da Simplificação. 
Essa forma de abordagem da realidade é capaz de, por meio do diálogo, conceber a organização, reunindo, contextualizando e globalizando as singularidades, as individualidades, a concretude das coisas. Ele não ignora ou suprime as personalidades. Ao contrário, reconhece-as e respeita as suas características, e, de todo o seu potencial, procura se valer integralmente. Ao se aceitar que a realidade é aquilo que se percebe do que foi tecido conjuntamente, não se olvida a singularidade dos fios, que inclusive podem ser substancialmente diferentes, para pensar metaforicamente. ${ }^{7} \mathrm{E}$ isso é essencial ao conhecimento do Direito.

$\mathrm{O}$ ato de pensar a complexidade pode ser descrito, assim, como um edifício de vários andares, cuja base se constitui de três teorias fundamentais e que permitem criar uma teoria da organização (MORIN; LE MOIGNE, 2000):

a. a teoria da informação, em que as informações alimentam e resolvem, ${ }^{8}$ a um só tempo, as incertezas e a surpresa, e trazem as novidades;

b. a teoria cibernética, referindo-se às máquinas autônomas para ilustrar que as ações provocam retroações, feedbacks, de modo que as causas levam aos efeitos que, por sua vez, respondem às causas, e

c. a teoria dos sistemas, que lança as bases para se pensar a organização, uma vez que deixa claro que "o todo é mais do que a soma das partes", implicando dizer que a organização pode gerar qualidades e efeitos que poderão afetar, em retorno, às partes, levando inclusive à conclusão de que o todo é - ou pode ser - menos que a soma das partes, em razão de qualidades de cada parte serem inibidas com a organização do todo.

É sobre essa base que se erige o pensamento da complexidade, apoiando-se sobre ideias que cuidam da auto-organização ( 2 o andar), e, sobre essas, elementos que Morin e Le Moigne (2000) abordou, quais sejam, os Princípios que nomina como Dialógico, de Recursão e Hologramático (3ํandar):

a. o Princípio Dialógico como aquele que preconiza a união de noções diversas no momento de pensar os processos de organização, produção e criação em meio à complexidade humana; de modo que as lógicas envolvidas formem uma unidade complexa, ainda que antagônicas, acabando por alimentar uma à outra, integrando-se em uma unidade que se faz a partir do antagonismo, da concorrência e/ou da complementação;

\footnotetext{
De certo modo, o raciocínio empregado na Teoria da Causalidade exposta por Aristóteles ajuda a compreender essa colocação, sem embargo da pecha de ideológica que Ihe atribui Marilena Chauí (vide, por exemplo, sua obra Ideologia) e à qual fazemos oposição em vários aspectos, o que não cabe aqui discutir. Segundo essa teoria, o conhecimento de algo se dá a partir do conhecimento de suas causas, na verdade, variáveis a serem observadas (ou fios do tecido), sendo estas: causa material (a matéria que constitui algo), causa formal (a forma que a matéria assume ou que lhe é dada), causa eficiente (a ação/sujeito que imprime à matéria a forma) e causa final (a razão pela qual uma determinada forma é dada a algo). O conhecimento de tais causas representaria nossa percepção da realidade, e verificaríamos que existem materiais diferentes constituindo cada objeto (por exemplo, tipos de normas), e que a forma (por exemplo, texto escrito e hierarquia) de cada um destes seria ditada conforme sua causa eficiente (quem tivesse poder para fazê-lo) com uma determinada finalidade (estabelecer uma ordem a partir de interesses e valores tidos como relevantes por qualquer motivo). Todas essas variáveis podem se alterar de sociedade para sociedade, de tempo para tempo, de espaço para espaço.

8 Aqui Morin refere-se à ambivalência das informações, que a um só tempo podem resolver incertezas e alimentar (até mesmo criar) outras, especialmente se forem consideradas a pluralidade e a complexidade.
} 
b. o Princípio da Recursão como o que ultrapassa o Princípio da Retroação (feedback, que mantém indivíduos e sistema apartados, adotando uma causalidade linear, na qual os efeitos não agem sobre suas causas), considerando-se que há formação de um círculo gerador, no qual há autoprodução e auto-organização, de modo que os produtos e efeitos de um sistema são também componentes do sistema que os produz, assumindo a posição de produtores e causadores; tal como ocorre com os indivíduos, que têm sua humanidade traçada pela sociedade, mas que a esta se acoplam, e, mediante suas interações, produzem a sociedade que Ihe dá seu legado (cultura e linguagem, por exemplo);

c. o Princípio Hologramático, no sentido de que existem sistemas em que as partes comporiam o todo, mas também conteriam a quase totalidade das informações deste todo, como, por exemplo, acontece com as células que, como partes, compõem um organismo (o todo), mas que trazem em si a totalidade do patrimônio genético desse organismo; o mesmo ocorreria com os indivíduos, que são as partes que compõem a sociedade, mas que teriam presente em si mesmos a própria sociedade por meio de sua linguagem, sua cultura e suas normas.

Repise-se: a proposta do pensar complexo aponta não para o abandono dos saberes desenvolvidos segundo o paradigma moderno tradicional, em que a simplificação, o cientificismo (e as "certezas") e a disciplinaridade prevalecem; e sim, para o reconhecimento de que a complexidade da realidade aponta para o diálogo entre saberes, disciplinas e sujeitos que, com sua diversidade e pluralidade (e incertezas), interagem e integram o todo social, locus em que os ideais democráticos e pertinentes à dignidade humana informam os discursos que sustentam os balizamentos jurídico-positivos da maior parte dos Estados, que estes buscam defender e assegurar.

Isso nos leva a problematizar como a Ciência Jurídica, pela perspectiva disciplinar do paradigma epistemológico tradicional, produziria atualmente conhecimentos voltados para a humanidade sob a égide da democracia.

Afinal, se a Ciência e o Direito, pela perspectiva democrática estampada nos discursos predominantes, devem servir à humanidade organizada em sociedades políticas e sem perder de vista os indivíduos e grupos em sua diversidade e pluralidade (tendo em vista o bem comum), ${ }^{9}$ como, então, poderiam ter seus balizamentos estabelecidos hegemonicamente apenas por um determinado grupo?

Exemplificando: poderia o Estado decidir, em benefício do todo social, se um investimento em agronegócio deveria ser permitido (e até incentivado) ou proibido (ou desestimulado), tendo em vista apenas a perspectiva de uma determinada parcela da

\footnotetext{
Bem comum significa aqui, essencialmente, a garantia de que todo indivíduo terá condições sociais de obter realizações pessoais compatíveis com o todo social e com sua dignidade de pessoa humana e em conformidade com as competências, habilidades e empenho. Significa idealmente que há tratamento efetivamente igualitário no seio socioestatal.
} 
sociedade, seja ela qual for? Como conciliar as diferentes perspectivas que se encontrariam em enfrentamento, com os impactos econômicos, sociais, culturais e ambientais provocados por tal investimento?

Qual o papel da Ciência em meio a esse conflito? Sob a perspectiva tradicional, e com apoio no Direito Positivo, seriam chamados especialistas para se pronunciarem; quais seriam as especialidades convocadas por intermédio de seus representantes (economistas, ambientalistas, antropólogos, sociólogos, epidemiologistas, etc.)? $\mathrm{Na}$ condição de especialidades, ofertando cada qual esclarecimentos sob sua perspectiva isolada, poderiam sustentar a decisão também isoladamente? Uma vez trazidos os argumentos e esclarecimentos perante as autoridades estatais, caberia determinar em qual(is) se apoiar, ainda que não tivessem formação em qualquer uma delas?

É evidente que a decisão deveria apoiar-se em conhecimentos válidos, e a produção destes haveria de ser baseada em fundamentos epistemológicos, teóricos e metodológicos igualmente válidos e legítimos, considerando-se os valores democráticos. Quais seriam eles, nessas condições? A escolha de uma especialidade para fundar a decisão não se mostraria pouco objetiva? E se outras perspectivas, também importantes, não tivessem sequer sido cogitadas, tendo em vista a necessidade primeira de se ter conhecimento prévio para vislumbrar tal importância? E qual perspectiva deveria "vencer", considerando-se que tal vitória haveria de se apoiar em referenciais que a determinassem?

As indagações anteriormente levantadas evidenciam claramente a insuficiência do paradigma epistemológico moderno ou tradicional para o enfrentamento efetivo de problemas advindos da complexidade nos tempos que correm, especialmente se a Ciência é convocada a cumprir o seu papel pragmaticamente.

O pensar complexo, nesse sentido, apresenta-se como paradigma emergente de incalculável valor, inclusive quando ultrapassa os limites da Academia, implicando considerar a multiplicidade e a variedade de interações tanto no âmbito de organizações de e entre sistemas, quanto de partes com estes e entre si, o que leva inequivocamente à existência de incertezas. Aí está a complexidade em toda sua pujança, no contexto real, no sentido mesmo atribuído a este termo por Nicolescu (2002) - "aquilo que é" (e que, por definição, se encontra "velado"), o que o levou e também a Morin e Freitas (apud JAPIASSU, 2006, p. 81) a afirmarem ser "impossível todo olhar global sobre o ser humano".

O real é para além do que se estabelece em convenções, ainda que estas visem, justamente, a conhecê-lo; isto porque o real é sempre descrito ou indicado de modo complexo e dinâmico, de forma que as simplificações disciplinares, que redundam em produção de conhecimentos profundos, mas produzidos sob perspectivas únicas e em searas estanques, não permitem conhecê-lo em sua integralidade dinâmica.

E é por isso que vale o esclarecimento de Nicolescu (2002), de que a Realidade é a forma como se percebe o que é real. A Realidade ou "aquilo que resiste às experiências, representações, descrições, imagens e mesmo às formulações matemáticas" é que é acessível ao conhecimento, sempre parcial, mas sempre em ampliação, é o que se acrescenta. Daí este autor ressaltar que existem Níveis de Realidade que variam conforme se alteram os níveis de percepção empregados na análise ou no estudo, todos 
válidos e legítimos, ultrapassando-se a ideia de que há transferências de conhecimentos somente a partir da Ciência moderna, implicando mesmo diálogo entre saberes, abrangendo a cultura e a religião.

Dessa forma, o saber científico tem crescido, mas apenas exponencialmente, posto que seu fundamento é o paradigma tradicional; esse crescimento ocorreu em razão do aprofundamento e da expansão do número de disciplinas (essencialmente fragmentadas e estanques), sem que houvesse o indispensável diálogo entre elas, o que permitiria a aproximação do conhecimento com aquilo que é real, pela ampliação mesma do nível de realidade, sob a ótica de Nicolescu (2002).

Esse diálogo entre as disciplinas e saberes conduz à sua interação, que pode se dar em formas e intensidades (ou níveis) variáveis, nomeados pelos que com eles se ocupam, ainda com certa ambiguidade (POMBO, 2017b; SOMMERMAN, 2006; MINAYO, 2016). Daí os termos pluridisciplinaridade, multidisciplinaridade, interdisciplinaridade e transdisciplinaridade serem empregados sem o devido domínio por parte da maioria dos utentes, o que é um fato, considerando-se válido o alerta de Pombo (2017b); ${ }^{10}$ qual seja, de que a simples reunião de especialistas de várias disciplinas em torno de uma mesa, na imensa maioria dos casos, tem muito mais a ver com a disciplinaridade do que com qualquer desses termos, dada "[...] a incapacidade que todos temos para ultrapassar os nossos próprios princípios discursivos, as perspectivas teóricas e os modos de funcionamento em que fomos treinados, formados, educados," que seria o paradigma moderno tradicional (POMBO, 2017b, p. 5). ${ }^{11}$

É preciso, portanto, esclarecer, no âmbito deste trabalho, pelo menos em suas linhas fundamentais, que as propostas que buscavam compensar essa especialização disciplinar despontaram da metade do século 20 em diante, e eram baseadas não no abandono das especialidades, mas na cooperação entre elas em diversos níveis, sendo denominadas inicialmente de multi e pluridisciplinares, e, posteriormente, de inter e de transdisciplinares, apresentando "cada um desses termos vizinhos [ ] muitas definições, [mas] no que diz respeito aos conceitos de multidisciplinaridade e de pluridisciplinaridade" haveria quase um consenso (SOMMERMAN, 2006, p. 28).

Vejamos suas pautas fundamentais:

a. multidisciplinaridade - aborda o emprego de disciplinas por mera justaposição simples, conservando cada uma delas suas teorias e metodologias conforme estabelecidas sob a perspectiva unidisciplinar fechada; a perspectiva multidisciplinar dá-se quando estudiosos de várias áreas são chamados para dissertar sobre um mesmo tema, o que fazem a partir de suas perspectivas unidisciplinares, contudo sem que mantenham entre si diálogo técnico-científico mais profundo; não deve ser confundida com a atuação multiprofissional ou multiprofissionalidade, que ocorreria, por exemplo, quando em um programa de extensão atuem cooperativamente médicos, odontólogos, juristas, etc.

\footnotetext{
${ }^{10} \mathrm{~A}$ autora utiliza como base para essas considerações a seguinte obra: GUSDORF, G. Les modéles épistémologiques dans les sciences humaines. Bulletin de Psychologie, n. 397, t. 43, fasc. 18, p. 858-68, 1990. O artigo de Pombo foi publicado em 2005 e acessado por nós em 2017, conforme explicitado nas Referências, ao final.

${ }^{11}$ A página indicada se refere à do artigo publicado por Pombo em 2005 e acessado por nós em 2017. 
(MINAYO, 2016); caracteriza-se, portanto, pela ausência de cooperação disciplinar e pela desnecessidade de nexo entre as abordagens, havendo objetivos múltiplos (SOMMERMAN, 2006);

b. pluridisciplinaridade - trata-se do emprego de disciplinas mais ou menos próximas, dentro de um mesmo setor de conhecimentos, o qual implica certo nível de relações de complementaridade, sem que haja, contudo, uma interação mais profunda e consistente, marcada, por exemplo, pela coordenação; persiste a multiplicidade de objetivos pertinentes a cada disciplina envolvida e sob sua perspectiva (SOMMERMAN, 2006);

c. interdisciplinaridade - é uma forma de interação que, sem que se perca de vista a unidisciplinaridade latente, dá-se a partir da articulação de duas ou mais disciplinas cujo foco concentra-se em objeto, problema ou tema complexo e que exige uma resposta ou análise que envolva a todas de uma só vez, podendo implicar transferências teóricas entre as disciplinas a ponto de gerar uma terceira, como a Bioquímica, por exemplo (ZABALA ${ }^{12}$ apud SOMMERMAN, 2006); a interdisciplinaridade provoca, nesse sentido, o diálogo disciplinar voltado para a construção de uma resposta ou análise a partir de sua interação, porém realizando cada uma das disciplinas envolvidas neste diálogo seus estudos essencialmente lastreadas na unidisciplinaridade latente, mas com postura dialogal proativa estratégica, a fim de que o esforço conjunto leve à compreensão, interpretação e explicação do objeto, do problema ou do tema complexos; cada disciplina presta sua contribuição, mantendo-se ainda em seus limites estreitos, muito embora se construam "aberturas" nestes limites por meio da cooperação no nível estabelecido, o que permite compartilhamento de conhecimentos disciplinares (MINAYO, 2016), podendo chegar ao nível de saberes oriundos de "práticas não científicas que incluem as instituições e atores sociais diversos (LEFF ${ }^{13}$ apud SOMMERMAN, 2006);

d. transdisciplinaridade - mostra-se como o produto final da interdisciplinaridade, no sentido de ser o ponto de chegada de seu desenvolvimento e intensificação, e compreende interação e abertura mais profundas dos limites disciplinares - "etapa superior de integração" (SANTOMÉ14 apud SOMMERMAN, 2006), por meio de esforço técnico-científico articulado entre os especialistas que atuam por meio de um diálogo muito mais intenso e livre, que permite a articulação teórica e conceitual, bem como metodológica (métodos, procedimentos e técnicas) para a busca de uma resultante que abarque a complexidade do objeto, tema ou problema (MINAYO, 2016); trata-se de construir um arcabouço teórico, conceitual e metodológico unificado, com dissolução

\footnotetext{
${ }^{12}$ Fonte consultada por Sommerman: ZABALA, Antoni. Enfoque globalizador e pensamento complexo. Porto Alegre: Artmed, 2002.

${ }^{13}$ Fonte consultada por Sommerman: LEFF, Enrique. Complexidade, interdisciplinaridade e saber ambiental. In: Interdisciplinaridade em Ciências Ambientais. São Paulo: Signus, 2000.

${ }^{14}$ Fonte consultada por Sommerman: SANTOMÉ, Jurjo Torres. Globalização e interdisciplinaridade. Porto Alegre: Artmed, 1998.
} 
das fronteiras entre disciplinas e diversas espécies de saberes, permitindo sua interpenetração e integração para o conhecimento do objeto, tema ou problema complexos.

Em qualquer caso, como bem observa Pombo (2017b), a existência mesma desses termos significa um forte movimento de resistência à especialização, expressão de um "esquartejar" da totalidade em divisões cada vez mais finas, formando um conjunto a partir do qual os cientistas pensam poder reconstituir posteriormente o todo, crendo ser este igual à soma de suas partes.

Nicolescu, Morin e Freitas ${ }^{15}$ (apud JAPIASSU, 2006, p. 81-83) consideram que essa proliferação de disciplinas na atualidade torna "impossível todo olhar global sobre o ser humano". Nesse sentido, a humanidade deve se preparar para enfrentar essa realidade de múltiplos níveis (que variam conforme muda o nível da percepção) e lógicas correspondentes. Para enfrentar este desafio é necessário assumir uma atitude marcada pelo rigor na argumentação, pela abertura ao desconhecido, ao incerto e ao inesperado, aos mitos, às religiões, às culturas diversas e pela tolerância às ideias e verdades contrárias, o que pode levar "a uma mutação comparável à passagem dos hominídeos à espécie humana". E é por este motivo que Nicolescu, Morin e Freitas ${ }^{16}$ (apud JAPIASSU, 2006, p. 83) afirmam no seu Manifesto da Transdisciplinaridade sobre a educação:

Artigo 11. A verdadeira educação não privilegia a abstração no conhecimento. Ensina a contextualizar, a concretizar e a globalizar. A educação transdisciplinar reavalia o papel da intuição, do imaginário, da sensibilidade e do corpo na transmissão dos conhecimentos.

Essa constatação permite inferir não só que a assunção desta base epistemológica de maneira geral mostrar-se-á sempre profícua, e em especial para as Ciências que têm objetos ligados ao humano e ao social, mas também que deve haver o desenvolvimento e o fortalecimento de base metodológica harmônica, de viés inter e transdisciplinar. Pode-se concluir, nesse sentido, que a aplicação do paradigma epistemológico emergente mostra-se muito mais consentânea com os ideais democráticos consagrados no Direito Positivo dos Estados do que a do paradigma moderno tradicional, sob todos os aspectos. Daí a proposta do pensar complexo e de seus corolários naturais, inter e transdisciplinaridade, mostrar-se mais do que uma alternativa, uma necessidade.

\section{CONSIDERAÇÕES FINAIS}

A complexidade do mundo em que vivemos nunca foi ignorada pela humanidade. O paradigma epistemológico moderno, contudo, que por séculos orientou a produção de conhecimento científico sobre tal realidade nos moldes expostos ao longo do desenvolvimento deste estudo, permitiu que os fenômenos fossem tratados de maneira extremamente simples, confiável e válida, levando a comunidade acadêmica a avançar de maneira e em ritmo que seria inacreditável antes de sua adoção.

\footnotetext{
${ }^{15}$ A obra citada por Japiassu foi a Charte de la transdisciplinarité, redigida por Basarab Nicolescu, Edgar Morin e Lima de Freitas, consultada na obra "Transdisciplinarité", Encyclopédie de L'Agora.

${ }^{16}$ A obra citada por Japiassu foi a Charte de la transdisciplinarité, redigida por Basarab Nicolescu, Edgar Morin e Lima de Freitas, consultada na obra "Transdisciplinarité", Encyclopédie de L’Agora.
} 
Assim foi se desenvolvendo a Ciência, até que, em muitos pontos, atingiu flagrantemente os limites de sua especialização disciplinar, não mais podendo se conter dentro destes. Não apenas no campo científico, todavia, a humanidade progrediu dessa forma. Também no campo político, no entendimento do que seria a dignidade da pessoa humana, no papel do Estado e da sociedade, isso ocorreu.

Começaram assim a ser traçadas as pautas de um novo paradigma epistemológico, que emergiu fundamentalmente a partir dessa chegada aos limites disciplinares e também dos avanços políticos havidos em torno da democracia e da dignidade da pessoa humana sob todos os aspectos, especialmente jurídico-positivos.

Essas mudanças, historicamente muito rápidas, conduziram desde seus primeiros momentos a uma revisão de tais limites disciplinares, e da forma como deveriam se desenvolver as Ciências, implicando ultrapassar (interdisciplinaridade) ou mesmo apagar (transdisciplinaridade) esses limites, dada a necessidade de enfrentamento da complexidade de outra maneira - pelo diálogo e pela interação disciplinar, pelo diálogo com outros saberes, que não os da Academia, aceitando a pluralidade e as diferenças.

Nesse sentido, o paradigma epistemológico emergente promove o diálogo e a interação entre sujeitos que são histórico-culturais e políticos e com as disciplinas, porém sem que ocorra o abandono de suas identidades amplamente consideradas, tanto sob a perspectiva disciplinar quanto sob a perspectiva humana.

Tratando de estudos e pesquisas conduzidos no campo da Ciência Jurídica, cujo objeto é o Direito Positivo, o pensar complexo, como base epistemológica, e a interdisciplinaridade e a transdisciplinaridade, como bases metodológicas, mostram-se perfeitamente adequados à produção de conhecimento científico conforme os ideais democráticos que devem informar toda e qualquer atividade humana em um Estado Democrático de Direito.

\section{REFERÊNCIAS}

ANDRÉS, Mauro Barroso. Globalização hegemônica e as novas exigências sociais: da necessidade de um novo paradigma educacional. Disponível em: <http://www.filologia.org.br/rph/66supl.html>. Acesso em: 25 jan. 2017.

BACHELARD, Gaston. O novo espírito científico. In: A filosofia do não; o novo espírito científico; a poética do espaço. Trad. Joaquim José Moura et al. São Paulo: Abril Cultural, 1978. (Coleção Os Pensadores).

BITTAR, Eduardo Carlos Bianca. Linguagem jurídica. 4. ed. São Paulo: Saraiva, 2009.

BOBBIO, Norberto. O positivismo jurídico: lições de filosofia do Direito. Compilação Nello Morra. Tradução e notas Márcio Pugliese, Edson Bini e Carlos E. Rodrigues. São Paulo: Ícone, 1995.

BRASIL. Constituição da República Federativa do Brasil de 1988. Disponível em: <http://www.planalto. gov.br/ccivil_03/constituicao/constituicaocompilado.htm>. Acesso em: 3 mar. 2018a.

Lei de introdução às normas do direito brasileiro. Disponível em: <http://www.planalto.gov.br/ ccivil_03/decreto-lei/Del4657compilado.htm>. Acesso em: 3 mar. 2018b.

DESCARTES, René. Discurso do método. Tradução Maria Ermantina Galvão. São Paulo: Martins Fontes, 1996.

DINIZ, Maria Helena. Compêndio de introdução à ciência do direito: introdução à teoria geral do direito, à filosofia do direito, à sociologia jurídica e à lógica jurídica: norma jurídica e aplicação do direito. 25. ed. rev. atual. São Paulo: Saraiva, 2014.

FERRAZ JÚNIOR, Tércio Sampaio. Introdução ao estudo do direito: técnica, decisão, dominação. 5. ed. rev. ampl. São Paulo: Atlas, 2007.

HABERMAS, Jürgen. Agir comunicativo e razão destrancendentalizada. Trad. Lúcia Aragão. Rev. Daniel Camarinha da Silva. Rio de Janeiro: Tempo Brasileiro, 2002. 
JAPIASSU, Hilton. O sonho transdisciplinar: e as razões da filosofia. Rio de Janeiro: Imago, 2006.

KUHN, Thomas S. A estrutura das revoluções científicas. Trad. Beatriz Viana Boeira e Nélson Boeira. 9. ed. São Paulo: Perspectiva, 2006.

KELSEN, Hans. Teoria pura do direito. Tradução João Baptista Machado. 6. ed. São Paulo: Martins Fontes, 1998.

MARQUES NETO, Agostinho Ramalho. A ciência do direito: conceito, objeto e método. 2. ed. Rio de Janeiro: Renovar, 2001.

MINAYO, Maria Cecília de Souza. Disciplinaridade, interdisciplinaridade e complexidade. Disponível em: $<$ https://www.google.com.br/url?sa=t\&rct=j\&q=\&esrc=s\&source=web\&cd=1\&cad=rja\&uact=8\&ved=0ahUKEwiPp_rirYHPAhUG6x4KHVdKAysQFggpMAA\&url=http\%3A\%2F\%2Fwww.revistas2.uepg.br\%2Findex.php\%2Femancipacao\%2Farticle\%2Fdownload\%2F1937\%2F1880\&usg=AFQjCNGYlejc4M4gcbOZ9hDolXkOuSOJ-A>. Acesso em: 8 set. 2016.

MONTESQUIEU, Charles de Secondat, Baron de. O espírito das leis. Apresentação Renato Janine Ribeiro. Tradução Cristina Murachco. 2. ed. São Paulo: Martins Fontes, 1996.

MORAES, Maria Cândida. O paradigma educacional emergente. 10. ed. São Paulo: Papirus, 2004.

MORIN, Edgar; LE MOIGNE, Jean-Louis. A inteligência da complexidade. Trad. Nurimar Maria Falci. São Paulo: Fundação Peirópolis, 2000.

MORIN, Edgar. Por uma reforma do pensamento. In: PENA-VEGA, Alfredo; NASCIMENTO, Elimar Pinheiro do (Org.). O pensar complexo: Edgar Morin e a crise da modernidade. 2. ed. Rio de Janeiro: Garamond, 1999.

Da necessidade de um pensamento complexo. In: MARTINS, Francisco Menezes; SILVA, Juremir Machado da. (Orgs.). Para navegar no século XXI: tecnologias do imaginário e cibercultura. 3. ed. Porto Alegre: Sulina; Edipucrs, 2003.

NICOLESCU, Basarab. Fundamentos metodológicos para o estudo transcultural e transreligioso. In: CETRANS. Educação e transdisciplinaridade II. São Paulo: Trion, 2002. Disponível em: <http://unesdoc.unesco.org/images/0012/001297/129707POR.pdf>. Acesso em: 7 fev. 2017.

POMBO, Olga. A interdisciplinaridade como problema epistemológico e exigência curricular. Disponível em: <http://cfcul.fc.ul.pt/textos/OP\%20-\%20Interdisciplinaridade\%20como\%20Problema\%20Epistemologico.pdf>. Acesso em: 25 jan. 2017a.

Interdisciplinaridade e integração dos saberes. Liinc em Revista, v. 1, n. 1, p. 3-15, mar. 2005. Disponível em: <http://liinc.revista.ibict.br/index.php/liinc/article/view/186/103>. Acesso em: 11 fev. 2017b.

REALE, Miguel. Horizontes do direito e da história. 3. ed. rev. aum. São Paulo: Saraiva, 2000.

Filosofia do direito. 18. ed. São Paulo: Saraiva, 1998.

ROBLES, Gregorio. El derecho como texto: en torno a la fundamentación de una teoria comunicacional del derecho. Persona y Derecho. Navarra: Servicio de Publicaciones de la Universidad de Navarra, v. 35, p. 195-226, 1996. Disponível em: <http://dadun.unav.edu/handle/10171/12908>. Acesso em: 21 jan. 2017. SANTOS, Boaventura de Sousa. A universidade do século XXI: para uma reforma democrática e emancipatória da universidade. Disponível em: <http://www.ces.uc.pt/bss/documentos/auniversidadedosecXXI. pdf>. Acesso em: 8 set. 2016.

Para uma sociologia das ausências e uma sociologia das emergências. Revista Crítica de Ciências Sociais, Coimbra, Portugal, n. 63, out. 2002.

SOARES, Ricardo Maurício Freire. Hermenêutica e interpretação jurídica. São Paulo: Saraiva, 2010.

SOMMERMAN, Américo. Inter ou transdisciplinaridade? Da fragmentação disciplinar ao novo diálogo entre os saberes. 2. ed. São Paulo: Paulus, 2006.

SOROS, George. A crise do capitalismo: as ameaças aos valores democráticos: as soluções para o capitalismo global. Trad. Afonso Celso da Cunha Serra. 5. ed. Rio de Janeiro: Campus, 1998.

STEIN, Ernildo. Prefácio. In: STRECK, Lenio Luiz. Hermenêutica jurídica e $(m)$ crise: uma exploração hermenêutica da construção do Direito. 11. ed. rev. atual. ampl. Porto Alegre: Livraria do Advogado, 2014.

STRECK, Lenio Luiz. Hermenêutica jurídica $e(m)$ crise: uma exploração hermenêutica da construção do Direito. 11. ed. rev. atual. ampl. Porto Alegre: Livraria do Advogado, 2014.

TELLES JÚNIOR, Goffredo. Iniciação na ciência do direito. 2. ed. São Paulo: Saraiva, 2002. 